\title{
Rheumatoid Arthritis and the Role of VEGF Gene: An Overview
}

\author{
Mohsin Mumtaz ${ }^{1}$, Nageen Hussain ${ }^{2}$ \\ ${ }^{1}$ Department of Microbiology and Molecular Genetics, University of the Punjab, Lahore 54590, \\ Pakistan. \\ ${ }^{2}$ Assistant professor, Department of Microbiology and Molecular Genetics, University of the Punjab, \\ Lahore 54590, Pakistan.
}

\begin{tabular}{|c|c|}
\hline \multirow{5}{*}{$\begin{array}{l}\text { Article Info } \\
\text { Article histor } \\
\text { Received: } 01 \\
\text { Revised: } 03\end{array}$} & \multirow{11}{*}{$\begin{array}{l}\text { Abstract } \\
\text { Purpose: The aim of this review study is to outline rheumatoid arthritis } \\
\text { and VEGF participation in rheumatoid arthritis disease development and } \\
\text { also to help future researchers in this field. } \\
\text { Study Design: A Review Study. } \\
\text { Subjects and Methods: A number of research articles were systematically } \\
\text { reviewed. More sixty research studies related to rheumatoid arthritis and } \\
\text { the role of VEGF Gene were examined. The results of these studies are } \\
\text { highlighted and compared. } \\
\text { Results: Rheumatoid Arthritis is capable of causing joint damage, } \\
\text { moreover, lead to long term disability in severe cases. Mutation in VEGF } \\
\text { due to the involvement of multiple factors (environmental, genetic factors } \\
\text { etc) lead to severity in RA patients as it has a role in certain inflammatory } \\
\text { processes, angiogenesis etc. Further research needs to be done in this field } \\
\text { because many of the factors involve in pathogenesis of RA such as factors } \\
\text { that cause loss of tolerance and inflammation in joints, are still unclear. } \\
\text { Conclusion: Although old diagnostic techniques are optimized, we further } \\
\text { need to improve the diagnostic and treatment techniques in order to } \\
\text { diagnose the patients at early stage. This will pacify patients' disease } \\
\text { severity and provide certain preventive measure that will assist in } \\
\text { preventing the aggravation of disease in family members. }\end{array}$} \\
\hline & \\
\hline & \\
\hline & \\
\hline & \\
\hline & \\
\hline & \\
\hline & \\
\hline & \\
\hline & \\
\hline & \\
\hline
\end{tabular}

\section{Introduction}

Rheumatoid arthritis is an inflammatory autoimmune disease and particularly correlating innate immunity with cognate immunity. Progression of RA involves dysregulation of homeostatic processes that lead to disturbance in pathological processes (Boissier, 2011). Females are more affected with RA as compared to males and in a population its prevalence ranges from 0.5 to $1 \%$ on the basis of regional variations (Silman \& Pearson, 2002). RA mainly affects the synovial joints (lining) and can cause disability and premature death. The clinical presentation of RA involves redness, swelling, pain in joint (RA involve two or more joints) and restrictive range of motion of joint. In early diagnosis of RA (less joint destruction, no functional disability and a reduced amount of radiologic progression), improvement of affected joints can most possibly be achieved to desired level by giving treatment (involve DMARD medication) up to the first 12 weeks after appearance of early symptoms (Cho et al., 2019; Moura et al., 2015; Linden et al., 2010).

Dimeric glycoprotein (VEGF) have role in angiogenesis (formation of new blood vessels) and also play fundamental role in the migration and proliferation endothelial cells, 
wound healing processes, in certain embryonic developmental stages, increases the vascular permeability of new blood vessels and also in tumor development mechanisms (Kowanetz \& Ferrara, 2006). Expression of VEGF is in platelets, neutrophils, macrophages, smooth muscle cells(Hamamichi et al., 2001). There are considerable evidences that there is certain relationship between VEGF gene and autoimmune disorders like rheumatoid arthritis, systemic lupus erythematosus, multiple sclerosis (Carvalho, Blank, \& Shoenfeld, 2007). In RA patients, VEGF along with its receptors express in the synovial fluid of inflamed joints (Fava et al., 1994; Han et al., 2004; Ikeda, Hosoda, Hirose, Okada, \& Ikeda, 2000). In synovial fluid and serum of RA patients, increase in the expression of VEGF level was observed and also showed association with angiogenesis, destructive changes, inflammatory markers, pathological conditions and disease activity of rheumatoid arthritis patients (Ballara et al., 2001; Clavel et al., 2007; Fava et al., 1994; S. Lee et al., 2001; Sone et al., 2001).

Immune system protects the organisms from invading pathogens and has ability to recognize agents of wide variety. Aside from protection, it is also capable of distinguishing self from non-self and healthy molecules from non-healthy molecules (Sanabria, Goring, Nürnberger, \& Dubery, 2008). Self Antigens recognition play fundamental role in modulating TCR and BCR, thereby, causing hindrance in the production of auto reactive cells. Henceforth, generate mechanism of tolerance that reduces autoimmune disease susceptibility (Zen et al., 2013). Under certain circumstances, immune response misdirects and starts attacking the body cells itself. In other words, the term "autoimmunity" refers to abnormal immune system activation that leads to inflammation of tissue and deterioration in genetically susceptible individuals (Gratz et al., 2014). The circulating auto Abs reacts with normal cells, tissues and cause organ damage that ultimately proceeds to autoimmune disorders such as systemic sclerosis, Rheumatoid arthritis (RA), Sjogrens' syndrome and Systemic lupus erythematosus (SLE).

Rheumatoid arthritis is an autoimmune disease (chronic disease) in which two antibodies namely (ACPA) anti citrullinated peptide antibody and rheumatoid factor (RF) express outside or inside the joints and react with common auto-antigens. In all phases of disease environment and genes interaction play crucial role. Moreover, not only imbalance of cytokine cause joint destruction but also dysregulation of matrix production, osteoclast regulator osteoprotegerin and Wingless-related integration site system (signalling pathway) defect cause cartilage damage (Boissier, Semerano, Challal, Saidenberg-Kermanac'h, \& Falgarone, 2012). Some issues are still unsolved. In some cases, auto-antibodies (ACPA and $\mathrm{RF}$ ) are detected before rheumatoid arthritis development and in some series, increased level of these reactive auto-abs have been observed that depict the onset of rheumatoid arthritis approaches (Rantapää-Dahlqvist et al., 2003).

Osteoarthritis is degenerative disease of joints and it affects more than $25 \%$ of population that is over 18-year age. Pathology of OA involves progressive loss and damage of articular joints, osteophytes formation, inflammation of synovium and damage of ligament (Loeser, Goldring, Scanzello, \& Goldring, 2012). Rheumatoid arthritis (RA) can be distinguished from Osteoarthritis as RA affects multiple joint at the same time and also involve other complications. Most commonly, it affects more seriously some of the joints and symmetrically (Frank-Bertoncelj et al., 2017). Immune system attacks the membrane lining 
that surrounds the joint called synovium and cause inflammation that destroy the cartilage within bone. This disease is characterized by formation of (new) blood vessels from already existing blood vessels to supply growth factors, nutrients, cytokines, oxygen to augment the inflammatory process and pannus formation (pre-natural or irregular layer of fibrous tissues) that ultimately lead to joints destruction (Azizi, Boghozian, \& Mirshafiey, 2014; Carvalho et al., 2007; Hah et al., 2013; Han et al., 2004).

\section{Literature Review}

\section{Prevalence}

Rate of occurrence of RA is 1 percent worldwide and it is more common in females as compared to males (Markenson, 1991). Studies conducted in Northern part of America and Europe show 0.5 - $1.1 \%$ prevalence of RA while lower prevalence of RA found in Southern Europe that is $0.3-0.7 \%$ (Carmona et al., 2002; Guillemin et al., 2005; Saraux et al., 1999; Symmons et al., 2002). Low prevalence rate found in developing countries such as in Philippines $0.17 \%$ and in rural Africa is $0.0026 \%$ (Brighton, Badenhorst, \& Myers, 1988). The few findings reflect that RA prevalence less in developing countries because of the difference in distribution of age groups, moreover, mild RA cases may escape diagnosis due to limited health care facilities that lead to underestimation of RA prevalence in developing countries (Alamanos, Voulgari, \& Drosos, 2006). The research conducted in India and Pakistan illustrated the prevalence of rheumatoid arthritis (RA) was higher in India (0.2 $1 \%)$ as compared to Pakistan $(0.5 \%)$ because of diversity in Indian population (Akhter, Bilal, \& Haque, 2011).

\section{Male to female ratio of $\mathrm{RA}$}

RA is more frequent in females as compared to males and its ratio is $3: 1$. The mechanism behind why females are more susceptible to RA as compared to males is still unclear. Accordingly, hormonal changes are the major contributor in the onset of disease in women. The age at which women are more prone to RA is fifth decade at which most of the hormonal changes (estrogens level) occur (Tobón, Youinou, \& Saraux, 2010).In females, both hormonal and reproductive factors have important role in the development and expression of RA. Several studies suggest that the use of oral contraceptives might offer some protective affect from developing rheumatoid arthritis or might delay its expression (Harrison \& Symmons, 2000). Whereas RA incidence declines by $70 \%$ during pregnancy but its incidence significantly increases to five fold during the first 3 months of post partum(A. Silman, Kay, \& Brennan, 1992). Moreover, breast feeding also show association in the progression of RA. According to recent research, risk of developing RA increases by five fold in breast feeding women as compared to non-breast feeding women. Although the mechanism is still unknown but according to recent studies it might be due to increase in the secretion of prolactin hormone (Brennan \& Silman, 1994). Decrease in level of testosterone has been observed in RA affected males (Cutolo et al., 2002). 


\section{Risk factors}

Multiple factors (including genetics, sex and environmental factors) involve in expression of rheumatoid arthritis. Environmental factor i-e smoking factor, dietary contents, infectious microbes, silica exposure also contribute in aggravating the state of patient suffering from RA. However, some of these factors require further researches for elaboration (J. S. Smolen et al., 2018).

\section{Genetic factors}

RA show strong genetic association. According to twin studies, genetic factor contribute to RA nearly $60 \%$ (MacGregor et al., 2000). This pertains to ACPA positive RA patients while disease estimates are lower in sero negative patients (Padyukov et al., 2011; Stahl et al., 2012). Although, twins (identical) show a concordance of only $12-15 \%$ that implicates non coding factors also have role in RA susceptibility (J. S. Smolen et al., 2018). Several genes involve in RA susceptibility and disease severity such as $H L A-D R B 1, M M P 9$, SPAG16, IL2RA, GRZB and DKK1 (Krabben, Huizinga, \& van der Helm-van Mil, 2015; Viatte et al., 2016).

\section{Environmental factors}

Environmental factor can induce alteration in cellular activity by causing DNA methylation. For instance, higher methylation level found in smokers with ACPAs positive and carried risk allele HLA-DRB1 as compared to those who did not have this risk allele. However, in non-smoker this difference (methylation level) was not observed (Meng et al., 2017).

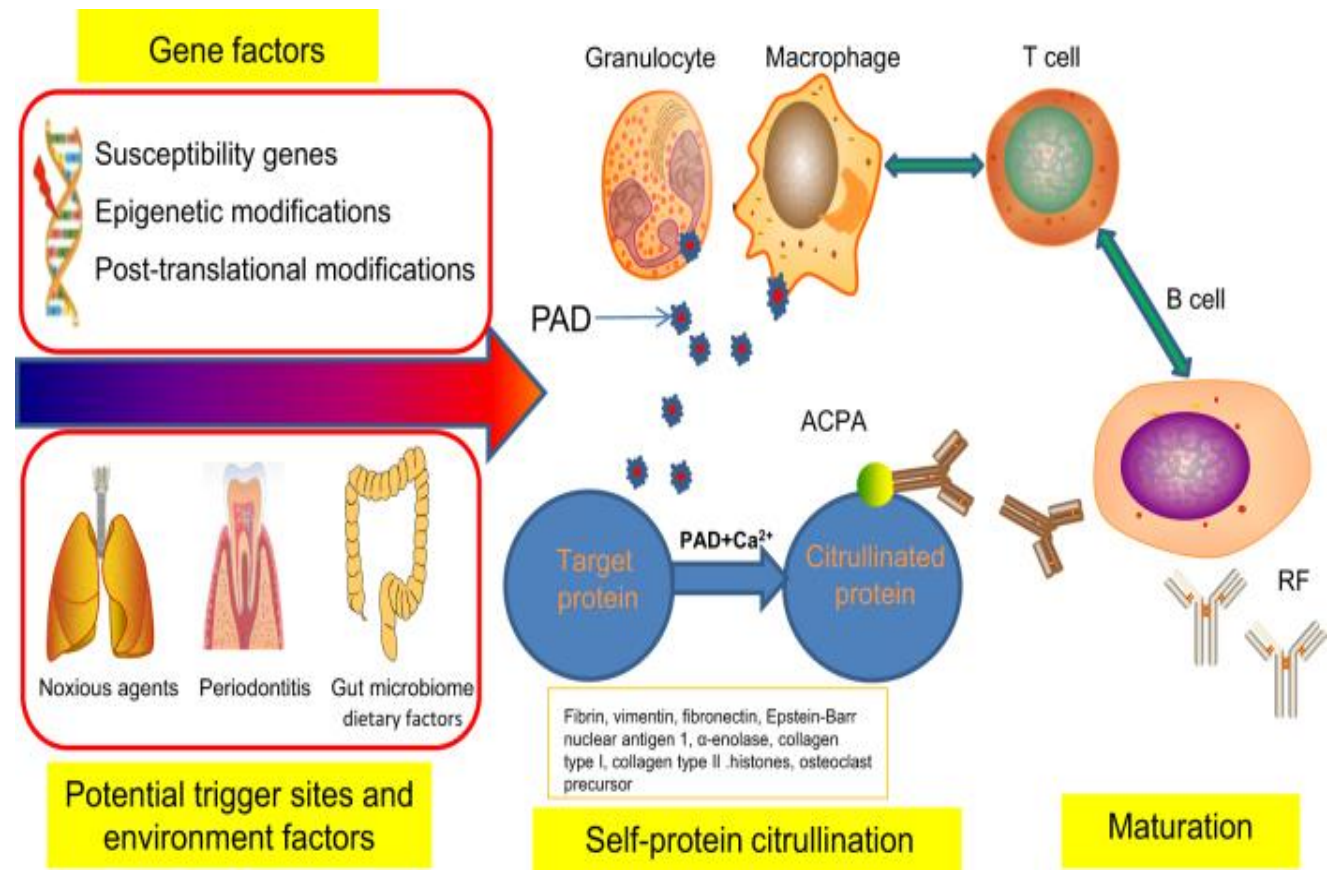

Figure-1: Contribution of environmental factors in Rheumatoid arthritis. 
Genes of potential trigger sites, as shown in figure 1, like oral, gut, lungs etc interact with environmental factors that cause initiation of self-protein citrullination and resulted in auto-antibodies production against peptides (citrullinated). Exposure of lungs to infectious agents, dietary contents, gut microbiota and harmful agents may cause the citrullination of self-protein and also ACPA maturation. PAD (peptidyl-argnine-deiminase) enzyme have role in the catalyzation of citrullination by modifying arginine (positively charged) to a polar but neutral citrulline during post translational modification. PAD enzyme secreted by macrophages and granulocytes in case of RA patients. Citrullinated proteins that include histones, fibrin, fibronectin, vimentin, Epstein-Barr Nuclear antigen 1 are disseminated throughout the body and abnormal reaction of antibodies to this wide range of protein (citrullinated) result in ACPA response. The citrullination mechanism also activate the MHC class II-dependent $\mathrm{T}$ cells that in turn boost $\mathrm{B}$ cells to enhance the production of ACPA. This stage also termed as loss of tolerance (Guo et al., 2018).

\section{Smoking}

Further research on RA demonstrates smoking was observed as a key factor in the rheumatoid arthritis disease development. Chances of RA risk increases by 2 folds in smokers that smoke 40 packs or more per year as compared to non-smokers and the risk still persist even after discontinuation of smoking. The Smoking effect is also influence by genetic background. The risk of rheumatoid arthritis increases by 21 folds in smokers having shared epitope and carrying two copies of it, as compared to non-smokers and having no shared epitope (Klareskog et al., 2006).

\section{Dietary Factors}

Dietary factor also play fundamental role in susceptibility of RA. Population consuming food rich in omega 3 fatty acid (fish, olive oil in cooking of food) have shown protection against RA. Omega 3 fatty acids have anti-inflammatory effect and reduce the inflammatory mediators through the pathway i.e. prostaglandin and leukotriene (James, Gibson, \& Cleland, 2000). According to several studies people of Southern Europe showed mild RA than other population. Food with high content of vitamin $\mathrm{K}$ and vitamin $\mathrm{D}$ (in legumes and vegetables) inhibit the fibroblast proliferation and reduce inflammation in RA (Tobón et al., 2010). Vitamin D has been employed as therapeutic factor in multiple autoimmune diseases i.e. RA, SLE(Kamen et al., 2006), multiple sclerosis (Hernan, Olek, \& Ascherio, 1999; Munger, Levin, Hollis, Howard, \& Ascherio, 2006), type 1 diabetes(Arnson, Amital, \& Shoenfeld, 2007). Vitamin D has numerous functions as it augment the regulation anti-inflammatory cytokine while suppress the proinflammatory cytokines (Canning, Grotenhuis, de Wit, Ruwhof, \& Drexhage, 2001) and the vitamin D receptor have role in regulation of adaptive and innate immune response (Arnson et al., 2007).

Normal body function also depend on iron level and deficiency of iron in RA patients may lead to anaemia and may impede the normal immunological response (Baker \& Ghio, 2009). Interlinking mechanism of interleukin 6, hormones that regulate iron level, cytokines (pro inflammatory), ferroprptein and hepcidin disturb the iron homeostasis and may lead to anaemia along with inflammation (Fraenkel, 2017). Properly dealing with anaemic condition 
can help in improving the lifestyle and physical activity of rheumatoid arthritis patients (Weiss \& Schett, 2013). According to recent research, natural low fat diet might provoke the pathways that lessen the disease severity (joint pain and inflammation) and has been observed through marking decreased CRP level and improvement in the inflammatory scores (Alwarith et al., 2019).

Increased level of oxidative stress has been observed in RA patients. In literature review, increase in the production of reactive oxygen species (ROS), protein oxidation, damage of DNA, lipid peroxidation and reduction in anti-oxidant system has been marked in RA patients (Mateen, Moin, Shahzad, \& Khan, 2017). In one study including 40 RA patients (only women), were supplemented with $8 \mathrm{mg}$ of zinc, $125 \mathrm{mg}$ of vitamin C, 50ug of selenium, $40 \mathrm{mg}$ of vitamin $\mathrm{E}$ and $400 \mathrm{ug}$ of vitamin $\mathrm{A}$, lessen the oxidative stress level and improved the clinical symptoms. In this study, considerable improvement in disease activity score was observed but not significant difference marked in swollen joints and painful condition of patients. The increased level of antioxidants in erythrocytes was also observed (Jalili, Kolahi, Aref-Hosseini, Mamegani, \& Hekmatdoost, 2014). In another research, supplementation of antioxidant vitamins (vitamin C, vitamin A) along with trace elements (zinc, copper) had proven no significant influence in the disease activity of RA (Keysser, 2001).

\section{Potential Agents}

In view of previous studies, susceptibility to RA can also be induced by the active involvement of potential agents and those agents also trigger disease development in host. Several potential agents associated with RA that includes rubella virus, Epstein Barr virus, parvovirus and other microbial pathogens. Patient's sera contain high titre of these infectious agents. Although, the role of these pathogens in disease occurrence still remain controversial. Moreover, there was no direct association found between these agents and RA patients (A. Silman et al., 1997; Alan J Silman \& Hochberg, 2001). Gut microbiome has a key role in the pathophysiology of rheumatoid arthritis. Intestinal membrane permeabilization allow the food particles or bacterial toxins (endotoxins) to enter into the blood stream and these endotoxins trigger the (systemic) inflammatory response (Pendyala, Walker, \& Holt, 2012). The variety of gut microbe's decrease in RA infected individuals compared with control (normal) population. The diversity of rare microbes such as actinobacteria are increased in RA patients while the variety of abundant microbiome of gut is reduced (Chen et al., 2016) The absorption of these endotoxins in blood stream sometime induce the initiation of proinflammatory $\mathrm{T}$ cells and autoantibodies production in RA patients (Chen et al., 2016; McDougall, Bruce, Spiller, Westerdahl, \& McDougall, 2002; Simpson \& Campbell, 2015). The recent research suggested gum inflammation caused by Porphyromonas gingivalis also have role in the pathogenesis of RA (Lundberg, Wegner, Yucel-Lindberg, \& Venables, 2010; Mikuls, 2010; Mikuls et al., 2009). The current proposition is that human peptides citrullination caused by Porphyromonas gingivalis may be involved in initiation of breakdown of self tolerance mechanism and lead to autoimmunity like RA (Lundberg et al., 2008; Wegner et al., 2010). Periodontal disease share similarities with RA pathogenesis like bone erosion along with inflammation and chronic inflammatory response while clinically they are very distinct. Both diseases (periodontal and RA) thought to be augmented by oral 
microbiota i.e. Aggregatibacter actinomycetemcomitans(Konig et al., 2016) and Porphyromonas gingivalis (Kharlamova et al., 2016).

\section{Pollutants}

Silica exposure have also shown association with increased risk of developing RA as it is environmental risk factor (Stolt et al., 2005). During the collapse of World Trade Centre in New York in 2001, rescue responders and fire fighters exposed to dust particulates and showed an increased risk association with autoimmune disorders including RA(Webber et al., 2015). The dust particulates contain different materials like silica, pulverized cement, asbestos, glass fibres. Occupational exposures also show association with RA. For instance, Malaysian women exposed to textile dust were shown strong association with increasing risk of developing rheumatoid arthritis (Too et al., 2016). Exposure to silica dust was a risk factor for seropositive (RF+ and ACPA+) RA patients but not a risk factor for seronegative patients. In occupations like mining, rock drilling and sand blasting exposure to silica through respiratory tract also show association in increasing the risk of RA development (Klockars, Koskela, Järvinen, Kolari, \& Rossi, 1987; Sluis-Cremer, Hessel, Hnizdo, \& Churchill, 1986; Steenland, Sanderson, \& Calvert, 2001; Turner \& Cherry, 2000). Increased exposure to dust (containing silica) can result in fibrosis and chronic inflammation of lungs, and hence provoke the humoral immunity that ultimately leads to increased risk of RA (seropositive patients). Moreover, occupational exposure to other parameters such as mineral oil (direct exposure of dust particle with skin and lungs) was also observed in epidemiological Investigation of RA (EIRA) (Sverdrup et al., 2005).

\section{Diagnosis}

Diagnosis of RA is highly specific and diagnosed by rheumatologist. However, no proper diagnostic criteria available but certain classification criteria present that involve serological assay (reactive c protein and auto antibody) and clinical manifestation. Swelling of synovial joints along with morning stiffness and tenderness in joints on examination is the important clinical feature of RA (J. S. Smolen et al., 2018). Very specific joints involve in RA that distinguish it from other joint disorders. It encompasses proximal interphalangeal and metacarpophalangeal joints of the feet, hand, ankle, wrist, elbow, shoulder, hip joints and knee (Smolen et al., 1995).

\section{Treatment}

The treatment of RA involves methotrexate and steroids (glucocorticoids). Optimal dose ( $25 \mathrm{mg}$ once in a week) of methotrexate should be given to patient that substitutes the folate in order to alleviate or pacify the adverse effects of disease. However, higher dose (more than used in RA) of methotrexate cause anti-proliferative effects but it does not follow the folate pathway(Ede et al., 2001). In early diagnosis, glucocorticoid along with methotrexate is given to the patient within 6 months to recover from severe disease activity. The efficiency of these two steroids never surpassed the effectiveness of synthetic disease modifying anti-rheumatic drugs (DMARDs) (J. Nam et al., 2014). 


\section{Genes Involved in RA Pathogenesis}

Multiple genes involve in the pathogenesis of RA. These genes include HLA gene with shared epitope and some other non-HLA genes with single nucleotide polymorphism such as VEGF, CTLA4, STAT4, PAD14, PTPN22, TRAF1, IRF5, IL23R and CCR6. More than 30 loci involve in the pathogenesis of RA, according to the recent genome wide association studies (Kurkó et al., 2013).

\section{VEGF Gene}

The VEGF gene is located on human chromosome 6p21.3 and comprised of eight exons with alternate splicing (Zhang et al., 2013). Heparin binding protein encoded by VEGF gene that exist as disulphide linked homo-dimer, this growth factor (VEGF) induce vascular endothelial cells migration and proliferation, therefore, play crucial role in angiogenesis (new blood vessels formation) (Merete Lund Hetland et al., 2008; M. L. Hetland et al., 2008). VEGF have also important role in certain pathological conditions that involve embryo development, healing of wound, endometrium formation, placenta, corpus luteum, neovascularisation, cardiovascular diseases, tumor formation and certain autoimmune diseases (Carvalho et al., 2007).

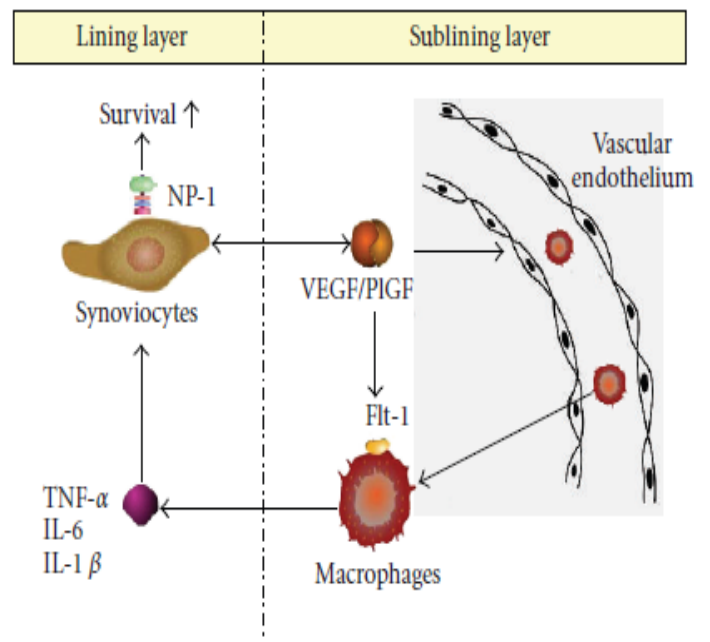

Figure-2: Role of VEGF gene in RA.

It has been dissertated that endothelial cells activated by VEGF produce chemokines for example IL-8 and MCP-1, as shown in figure 2 (T.-H. Lee, Avraham, Lee, \& Avraham, 2002; Marumo, Schini-Kerth, \& Busse, 1999). In synovial membrane, these chemokines function as recruiting the monocytes around the endothelial cells and existed macrophages, in synovial membrane produce IL-6 and TNF- $\alpha$ by interacting with either endothelial cells (activated) or VEGF. In return, these IL- 6 and TNF- $\alpha$ augment the capacity of synoviocytes and macrophages to secrete VEGF and endothelial cells stimulation thus induce the cell contact macrophage mediated activation, generating a positive feedback mechanism. Hence, VEGF may serve as fundamental link between synoviocytes and endothelial cells (Yoo, Kwok, \& Kim, 2008). 
VEGF induces pro-inflammatory changes that encompass accumulation of leukocytes, remodelling of blood vessels, collagen deposition and also increase in vascular permeability in chronic inflammation (Merete Lund Hetland et al., 2008; E. J. Nam et al., 2005; Yoo et al., 2008). Recently, it is documented that VEGF is critically required for rheumatoid synoviocytes survival (Kim et al., 2006). In previous studies, it has been demonstrated recombinant VEGF ligation to its receptors, induced by sodium nitroprusside (SNP) or serum starvation, prevent the synoviocytes apoptosis. The pAkt pathway and pERK activity rapidly stimulated by VEGF and then induce the Bcl-2 expression in RA synoviocytes. Moreover, Sodium nitroprusside induced $\mathrm{Bcl}-2$ down regulation and translocation of Bax, completely blocked by VEGF, from cytosol to mitochondria (Yoo et al., 2008).

VEGF level in patient's serum determine the severity of disease or disorder. The expression level of VEGF was observed more in synovial fluid and in serum of rheumatoid arthritis patients as compared to osteoarthritis patients (S. Lee et al., 2001; Ozgonenel et al., 2010). The over expression of VEGF is related with disease activity, inflammatory changes, damage in joints and in angiogenesis (E. J. Nam et al., 2005). VEGF up regulation induced by inflammatory cytokines and hypoxic state persists in RA patients (Taylor, 2005).

\section{Conclusion and Suggestion}

Rheumatoid Arthritis is capable of causing joint damage. Moreover, it leads to longterm disability in severe cases. Mutation in VEGF due to the involvement of multiple factors (environmental, genetic factors etc) lead to severity in Rheumatoid Arthritis patients as it has a role in certain inflammatory processes, angiogenesis etc. Further research needs to be done in this field because many of the factors involved in pathogenesis of RA such as factors that cause loss of tolerance and inflammation in joints, are still unclear. Although old diagnostic techniques are optimized, we further need to improve the diagnostic and treatment techniques in order to diagnose the patients at early stage. This will pacify patients' disease severity and provide certain preventive measure that will assist in preventing the aggravation of disease in family members.

\section{Conflict of Interest}

The authors of the article declare no conflict of interest.

\section{Funding:}

The authors received no funding for conducting this study.

\section{References}

Akhter, E., Bilal, S., \& Haque, U. (2011). Prevalence of arthritis in India and Pakistan: a review. Rheumatology international, 31(7), 849-855.

Alamanos, Y., Voulgari, P. V., \& Drosos, A. A. (2006). Incidence and prevalence of rheumatoid arthritis, based on the 1987 American College of Rheumatology criteria: a systematic review. Paper presented at the Seminars in arthritis and rheumatism. 
Alwarith, J., Kahleova, H., Rembert, E., Yonas, W., Dort, S., Calcagno, M., . . Barnard, N. D. (2019). Nutrition Interventions in Rheumatoid Arthritis: The Potential Use of Plant-Based Diets. A Review. [Review]. Front Nutr, 6(141).

Arnson, Y., Amital, H., \& Shoenfeld, Y. (2007). Vitamin D and autoimmunity: new aetiological and therapeutic considerations. [Review]. Ann Rheum Dis, 66(9), 11371142.

Azizi, G., Boghozian, R., \& Mirshafiey, A. (2014). The potential role of angiogenic factors in rheumatoid arthritis. International journal of rheumatic diseases, 17(4), 369-383.

Baker, J. F., \& Ghio, A. J. (2009). Iron homoeostasis in rheumatic disease. [Review]. Rheumatology, 48(11), 1339-1344.

Ballara, S., Taylor, P. C., Reusch, P., Marmé, D., Feldmann, M., Maini, R. N., \& Paleolog, E. M. (2001). Raised serum vascular endothelial growth factor levels are associated with destructive change in inflammatory arthritis. Arthritis \& Rheumatism: Official Journal of the American College of Rheumatology, 44(9), 2055-2064.

Boissier, M.-C. (2011). Cell and cytokine imbalances in rheumatoid synovitis. Joint Bone Spine, 78(3), 230-234.

Boissier, M.-C., Semerano, L., Challal, S., Saidenberg-Kermanac'h, N., \& Falgarone, G. (2012). Rheumatoid arthritis: from autoimmunity to synovitis and joint destruction. Journal of autoimmunity, 39(3), 222-228.

Brennan, P., \& Silman, A. (1994). Breast-feeding and the onset of rheumatoid arthritis. Arthritis \& Rheumatism: Official Journal of the American College of Rheumatology, 37(6), 808-813.

Brighton, S., Badenhorst, J., \& Myers, O. (1988). The prevalence of rheumatoid arthritis in a rural African population. The Journal of rheumatology, 15(3), 405-408.

Canning, M. O., Grotenhuis, K., de Wit, H., Ruwhof, C., \& Drexhage, H. A. (2001). 1alpha,25-Dihydroxyvitamin D3 $(1,25(\mathrm{OH})(2) \mathrm{D}(3))$ hampers the maturation of fully active immature dendritic cells from monocytes. [Research Support, Non-U S Gov't]. Eur J Endocrinol, 145(3), 351-357.

Carmona, L., Villaverde, V., Hernández-García, C., Ballina, J., Gabriel, R., \& Laffon, A. (2002). The prevalence of rheumatoid arthritis in the general population of Spain. Rheumatology, 41(1), 88-95.

Carvalho, J. F., Blank, M., \& Shoenfeld, Y. (2007). Vascular endothelial growth factor (VEGF) in autoimmune diseases. Journal of clinical immunology, 27(3), 246-256.

Chen, J., Wright, K., Davis, J. M., Jeraldo, P., Marietta, E. V., Murray, J., . . . Taneja, V. (2016). An expansion of rare lineage intestinal microbes characterizes rheumatoid arthritis. Genome medicine, 8(1), 43.

Cho, S. K., Kim, D., Won, S., Lee, J., Choi, C. B., Choe, J. Y., . . . Sung, Y. K. (2019). Factors associated with time to diagnosis from symptom onset in patients with early rheumatoid arthritis. Korean J Intern Med, 34(4), 910-916.

Clavel, G., Bessis, N., Lemeiter, D., Fardellone, P., Mejjad, O., Ménard, J.-F., . . Le Loët, X. (2007). Angiogenesis markers (VEGF, soluble receptor of VEGF and angiopoietin-1) in very early arthritis and their association with inflammation and joint destruction. Clinical Immunology, 124(2), 158-164.

Copyright (C) 2020, Journal of Scientific Research in Medical and Biological Sciences (JSRMBS), Under 
Cutolo, M., Villaggio, B., Craviotto, C., Pizzorni, C., Seriolo, B., \& Sulli, A. (2002). Sex hormones and rheumatoid arthritis. Autoimmunity reviews, 1(5), 284-289.

Fava, R. A., Olsen, N. J., Spencer-Green, G., Yeo, K.-T., Yeo, T.-K., Berse, B., . . Brown, L. F. (1994). Vascular permeability factor/endothelial growth factor (VPF/VEGF): accumulation and expression in human synovial fluids and rheumatoid synovial tissue. Journal of Experimental Medicine, 180(1), 341-346.

Fraenkel, P. G. (2017). Anemia of inflammation: a review. Medical Clinics, 101(2), 285-296.

Frank-Bertoncelj, M., Trenkmann, M., Klein, K., Karouzakis, E., Rehrauer, H., Bratus, A., . . - Michel, B. A. (2017). Epigenetically-driven anatomical diversity of synovial fibroblasts guides joint-specific fibroblast functions. Nature communications, 8 , 14852.

Gratz, I. K., Rosenblum, M. D., Maurano, M. M., Paw, J. S., Truong, H.-A., MarshakRothstein, A., \& Abbas, A. K. (2014). Cutting edge: Self-antigen controls the balance between effector and regulatory $\mathrm{T}$ cells in peripheral tissues. The journal of immunology, 192(4), 1351-1355.

Guillemin, F., Saraux, A., Guggenbuhl, P., Roux, C. H., Fardellone, P., Le Bihan, E., . . . Flipo, R.-M. (2005). Prevalence of rheumatoid arthritis in France: 2001. Annals of the rheumatic diseases, 64(10), 1427-1430.

Guo, Q., Wang, Y., Xu, D., Nossent, J., Pavlos, N. J., \& Xu, J. (2018). Rheumatoid arthritis: pathological mechanisms and modern pharmacologic therapies. Bone research, 6(1), $1-14$.

Hah, Y.-S., Koh, Y. J., Lim, H. S., Kim, H.-O., Cheon, Y.-H., Noh, H. S., . . Koh, G. Y. (2013). Double-antiangiogenic protein DAAP targeting vascular endothelial growth factor A and angiopoietins attenuates collagen-induced arthritis. Arthritis research \& therapy, 15(4), R85.

Hamamichi, Y., Ichida, F., Yu, X., Hirono, K.-I., Uese, K.-I., Hashimoto, I., . . Kanegane, H. (2001). Neutrophils and mononuclear cells express vascular endothelial growth factor in acute Kawasaki disease: its possible role in progression of coronary artery lesions. Pediatric research, 49(1), 74.

Han, S. W., Kim, G. W., Seo, J. S., Kim, S. J., Sa, K. H., Park, J. Y., . . Weyand, C. M. (2004). VEGF gene polymorphisms and susceptibility to rheumatoid arthritis. Rheumatology, 43(9), 1173-1177.

Harrison, B., \& Symmons, D. (2000). Early inflammatory polyarthritis: results from the Norfolk Arthritis Register with a review of the literature. II. Outcome at three years. Rheumatology, 39(9), 939-949.

Hernan, M. A., Olek, M. J., \& Ascherio, A. (1999). Geographic variation of MS incidence in two prospective studies of US women. [Research Support, U S Gov't, P H S]. Neurology, 53(8), 1711-1718.

Hetland, M. L., Christensen, I. J., Lottenburger, T., Johansen, J. S., Svendsen, M. N., Hørslev-Petersen, K., . . . Jørgen Nielsen, H. (2008). Circulating VEGF as a biological marker in patients with rheumatoid arthritis? Preanalytical and biological variability in healthy persons and in patients. Disease markers, 24(1), 1-10.

Copyright (C 2020, Journal of Scientific Research in Medical and Biological Sciences (JSRMBS), Under 
Hetland, M. L., Christensen, I. J., Lottenburger, T., Johansen, J. S., Svendsen, M. N., Horslev-Petersen, K., . . . Nielsen, H. J. (2008). Circulating VEGF as a biological marker in patients with rheumatoid arthritis? Preanalytical and biological variability in healthy persons and in patients. [Research Support, Non-U S Gov't]. Dis Markers, 24(1), 1-10.

Ikeda, M., Hosoda, Y., Hirose, S., Okada, Y., \& Ikeda, E. (2000). Expression of vascular endothelial growth factor isoforms and their receptors Flt-1, KDR, and neuropilin-1 in synovial tissues of rheumatoid arthritis. The Journal of pathology, 191(4), 426-433.

Jalili, M., Kolahi, S., Aref-Hosseini, S.-R., Mamegani, M. E., \& Hekmatdoost, A. (2014). Beneficial role of antioxidants on clinical outcomes and erythrocyte antioxidant parameters in rheumatoid arthritis patients. International journal of preventive medicine, 5(7), 835.

James, M. J., Gibson, R. A., \& Cleland, L. G. (2000). Dietary polyunsaturated fatty acids and inflammatory mediator production. [Review]. Am J Clin Nutr, 71(1 Suppl).

Kamen, D. L., Cooper, G. S., Bouali, H., Shaftman, S. R., Hollis, B. W., \& Gilkeson, G. S. (2006). Vitamin D deficiency in systemic lupus erythematosus. [Research Support, N I H , Extramural Review]. Autoimmun Rev, 5(2), 114-117.

Keysser, G. (2001). Are there effective dietary recommendations for patients with rheumatoid arthritis? Zeitschrift fur Rheumatologie, 60(1), 17-27.

Kharlamova, N., Jiang, X., Sherina, N., Potempa, B., Israelsson, L., Quirke, A. M., . . . Potempa, J. (2016). Antibodies to Porphyromonas gingivalis indicate interaction between oral infection, smoking, and risk genes in rheumatoid arthritis etiology. Arthritis \& rheumatology, 68(3), 604-613.

Kim, W.-U., Kang, S. S., Yoo, S.-A., Hong, K.-H., Bae, D.-G., Lee, M.-S., . . Cho, C.-S. (2006). Interaction of vascular endothelial growth factor 165 with neuropilin-1 protects rheumatoid synoviocytes from apoptotic death by regulating Bcl-2 expression and Bax translocation. The Journal of Immunology, 177(8), 5727-5735.

Klareskog, L., Stolt, P., Lundberg, K., Källberg, H., Bengtsson, C., Grunewald, J., . . . Rantapää-Dahlqvist, S. (2006). A new model for an etiology of rheumatoid arthritis: smoking may trigger HLA-DR (shared epitope)-restricted immune reactions to autoantigens modified by citrullination. Arthritis \& Rheumatism: Official Journal of the American College of Rheumatology, 54(1), 38-46.

Klockars, M., Koskela, R., Järvinen, E., Kolari, P., \& Rossi, A. (1987). Silica exposure and rheumatoid arthritis: a follow up study of granite workers 1940-81. Br Med J (Clin Res Ed), 294(6578), 997-1000.

Konig, M. F., Abusleme, L., Reinholdt, J., Palmer, R. J., Teles, R. P., Sampson, K., . . Giles, J. T. (2016). Aggregatibacter actinomycetemcomitans-induced hypercitrullination links periodontal infection to autoimmunity in rheumatoid arthritis. Science translational medicine, 8(369), 369ra176-369ra176.

Kowanetz, M., \& Ferrara, N. (2006). Vascular endothelial growth factor signaling pathways: therapeutic perspective. Clinical Cancer Research, 12(17), 5018-5022.

Krabben, A., Huizinga, T., \& van der Helm-van Mil, A. (2015). Biomarkers for radiographic progression in rheumatoid arthritis. Current pharmaceutical design, 21(2), 147-169.

Copyright (C) 2020, Journal of Scientific Research in Medical and Biological Sciences (JSRMBS), Under 
Kurkó, J., Besenyei, T., Laki, J., Glant, T. T., Mikecz, K., \& Szekanecz, Z. (2013). Genetics of rheumatoid arthritis - a comprehensive review. Clinical reviews in allergy \& immunology, 45(2), 170-179.

Lee, S., Joo, Y., Kim, W., Min, D., Min, J., Park, S., . . . Kim, H. (2001). Vascular endothelial growth factor levels in the serum and synovial fluid of patients with rheumatoid arthritis. Clinical and experimental rheumatology, 19(3), 321-324.

Lee, T.-H., Avraham, H., Lee, S.-H., \& Avraham, S. (2002). Vascular endothelial growth factor modulates neutrophil transendothelial migration via up-regulation of interleukin-8 in human brain microvascular endothelial cells. Journal of Biological Chemistry, 277(12), 10445-10451.

Loeser, R. F., Goldring, S. R., Scanzello, C. R., \& Goldring, M. B. (2012). Osteoarthritis: a disease of the joint as an organ. Arthritis \& Rheumatism, 64(6), 1697-1707.

Lundberg, K., Kinloch, A., Fisher, B. A., Wegner, N., Wait, R., Charles, P., . . Venables, P. J. (2008). Antibodies to citrullinated $\alpha$-enolase peptide 1 are specific for rheumatoid arthritis and cross-react with bacterial enolase. Arthritis \& Rheumatism: Official Journal of the American College of Rheumatology, 58(10), 3009-3019.

Lundberg, K., Wegner, N., Yucel-Lindberg, T., \& Venables, P. J. (2010). Periodontitis in RA - the citrullinated enolase connection. Nature Reviews Rheumatology, 6(12), 727.

MacGregor, A. J., Snieder, H., Rigby, A. S., Koskenvuo, M., Kaprio, J., Aho, K., \& Silman, A. J. (2000). Characterizing the quantitative genetic contribution to rheumatoid arthritis using data from twins. Arthritis \& Rheumatism: Official Journal of the American College of Rheumatology, 43(1), 30-37.

Markenson, J. A. (1991). Worldwide trends in the socioeconomic impact and long-term prognosis of rheumatoid arthritis. Paper presented at the Seminars in arthritis and rheumatism.

Marumo, T., Schini-Kerth, V. B., \& Busse, R. (1999). Vascular endothelial growth factor activates nuclear factor-kappaB and induces monocyte chemoattractant protein-1 in bovine retinal endothelial cells. Diabetes, 48(5), 1131-1137.

Mateen, S., Moin, S., Shahzad, S., \& Khan, A. Q. (2017). Level of inflammatory cytokines in rheumatoid arthritis patients: Correlation with 25-hydroxy vitamin D and reactive oxygen species. PloS one, 12(6), e0178879.

McDougall, J., Bruce, B., Spiller, G., Westerdahl, J., \& McDougall, M. (2002). Effects of a very low-fat, vegan diet in subjects with rheumatoid arthritis. The Journal of Alternative \& Complementary Medicine, 8(1), 71-75.

Meng, W., Zhu, Z., Jiang, X., Too, C. L., Uebe, S., Jagodic, M., . . Alfredsson, L. (2017). DNA methylation mediates genotype and smoking interaction in the development of anti-citrullinated peptide antibody-positive rheumatoid arthritis. Arthritis research \& therapy, 19(1), 71.

Mikuls, T. R. (2010). Help stop tooth decay... and prevent RA? : The Journal of Rheumatology.

Mikuls, T. R., Payne, J. B., Reinhardt, R. A., Thiele, G. M., Maziarz, E., Cannella, A. C., . . O'Dell, J. R. (2009). Antibody responses to Porphyromonas gingivalis (P. gingivalis)

Copyright (C) 2020, Journal of Scientific Research in Medical and Biological Sciences (JSRMBS), Under 
in subjects with rheumatoid arthritis and periodontitis. International immunopharmacology, 9(1), 38-42.

Moura, C. S., Abrahamowicz, M., Beauchamp, M.-E., Lacaille, D., Wang, Y., Boire, G., . . . Widdifield, J. (2015). Early medication use in new-onset rheumatoid arthritis may delay joint replacement: results of a large population-based study. Arthritis research \& therapy, 17(1), 197.

Munger, K. L., Levin, L. I., Hollis, B. W., Howard, N. S., \& Ascherio, A. (2006). Serum 25hydroxyvitamin D levels and risk of multiple sclerosis. [Research Support, N I H , Extramural Research Support, Non-U S Gov't]. Jama, 296(23), 2832-2838.

Nam, E. J., Han, S. W., Kim, S. U., Cho, J. H., Sa, K. H., Lee, W. K., . . . Kang, Y. M. (2005). Association of vascular endothelial growth factor gene polymorphisms with Behcet disease in a Korean population. Human immunology, 66(10), 1068-1073.

Nam, J., Villeneuve, E., Hensor, E., Conaghan, P., Keen, H., Buch, M., . . . Keenan, A. (2014). Remission induction comparing infliximab and high-dose intravenous steroid, followed by treat-to-target: a double-blind, randomised, controlled trial in new-onset, treatment-naive, rheumatoid arthritis (the IDEA study). Annals of the rheumatic diseases, 73(1), 75-85.

Ozgonenel, L., Cetin, E., Tutun, S., Tonbaklar, P., Aral, H., \& Guvenen, G. (2010). The relation of serum vascular endothelial growth factor level with disease duration and activity in patients with rheumatoid arthritis. Clinical rheumatology, 29(5), 473-477.

Padyukov, L., Seielstad, M., Ong, R. T., Ding, B., Rönnelid, J., Seddighzadeh, M., . . . Group, E. I. o. R. A. S. (2011). A genome-wide association study suggests contrasting associations in ACPA-positive versus ACPA-negative rheumatoid arthritis. Annals of the rheumatic diseases, 70(2), 259-265.

Pendyala, S., Walker, J. M., \& Holt, P. R. (2012). A high-fat diet is associated with endotoxemia that originates from the gut. Gastroenterology, 142(5), 1100-1101. e1102.

Rantapää-Dahlqvist, S., de Jong, B. A., Berglin, E., Hallmans, G., Wadell, G., Stenlund, H., . . van Venrooij, W. J. (2003). Antibodies against cyclic citrullinated peptide and IgA rheumatoid factor predict the development of rheumatoid arthritis. Arthritis \& Rheumatism, 48(10), 2741-2749.

Sanabria, N., Goring, D., Nürnberger, T., \& Dubery, I. (2008). Self/nonself perception and recognition mechanisms in plants: a comparison of self-incompatibility and innate immunity. New Phytologist, 178(3), 503-514.

Saraux, A., Guedes, C., Allain, J., Devauchelle, V., Valls, I., Lamour, A., . . . Le, P. G. (1999). Prevalence of rheumatoid arthritis and spondyloarthropathy in Brittany, France. Societe de Rhumatologie de l'Ouest. The Journal of rheumatology, 26(12), 2622-2627.

Silman, A., Bankhead, C., Rowlingson, B., Brennan, P., Symmons, D., \& Gatrell, A. (1997). Do new cases of rheumatoid arthritis cluster in time or in space? International journal of epidemiology, 26(3), 628-634. 
Silman, A., Kay, A., \& Brennan, P. (1992). Timing of pregnancy in relation to the onset of rheumatoid arthritis. Arthritis \& Rheumatism: Official Journal of the American College of Rheumatology, 35(2), 152-155.

Silman, A. J., \& Hochberg, M. C. (2001). Epidemiology of the rheumatic diseases: Oxford University Press.

Silman, A. J., \& Pearson, J. E. (2002). Epidemiology and genetics of rheumatoid arthritis. [Review]. Arthritis Res, 4(3), 9.

Simpson, H. L., \& Campbell, B. J. (2015). dietary fibre-microbiota interactions. Alimentary pharmacology \& therapeutics, 42(2), 158-179.

Sluis-Cremer, G., Hessel, P., Hnizdo, E., \& Churchill, A. (1986). Relationship between silicosis and rheumatoid arthritis. Thorax, 41(8), 596-601.

Smolen, J. S., Aletaha, D., Barton, A., Burmester, G. R., Emery, P., Firestein, G. S., . . . Yamamoto, K. (2018). Rheumatoid arthritis. [Review]. Nat Rev Dis Primers, 4(18001), 1.

Smolen, J. S., Eberl, G., Breedveld, F. C., Jones, I., Leeming, M., Wylie, G. L., \& Kirkpatrick, J. (1995). Validity and reliability of the twenty-eight-joint count for the assessment of rheumatoid arthritis activity. Arthritis \& Rheumatism: Official Journal of the American College of Rheumatology, 38(1), 38-43.

Sone, H., Sakauchi, M., Takahashi, A., Suzuki, H., Inoue, N., Iida, K., . . Okuda, Y. (2001). Elevated levels of vascular endothelial growth factor in the sera of patients with rheumatoid arthritis correlation with disease activity. Life sciences, 69(16), 18611869.

Stahl, E. A., Wegmann, D., Trynka, G., Gutierrez-Achury, J., Do, R., Voight, B. F., . . . Kurreeman, F. A. (2012). Bayesian inference analyses of the polygenic architecture of rheumatoid arthritis. Nature genetics, 44(5), 483.

Steenland, K., Sanderson, W., \& Calvert, G. M. (2001). Kidney disease and arthritis in a cohort study of workers exposed to silica. Epidemiology, 12(4), 405-412.

Stolt, P., Källberg, H., Lundberg, I., Sjögren, B., Klareskog, L., \& Alfredsson, L. (2005). Silica exposure is associated with increased risk of developing rheumatoid arthritis: results from the Swedish EIRA study. Annals of the rheumatic diseases, 64(4), 582586.

Sverdrup, B., Källberg, H., Bengtsson, C., Lundberg, I., Padyukov, L., Alfredsson, L., \& Klareskog, L. (2005). Association between occupational exposure to mineral oil and rheumatoid arthritis: results from the Swedish EIRA case-control study. Arthritis research \& therapy, 7(6), R1296.

Symmons, D., Turner, G., Webb, R., Asten, P., Barrett, E., Lunt, M., . . Silman, A. (2002). The prevalence of rheumatoid arthritis in the United Kingdom: new estimates for a new century. Rheumatology, 41(7), 793-800.

Taylor, P. (2005). Serum vascular markers and vascular imaging in assessment of rheumatoid arthritis disease activity and response to therapy. Rheumatology, 44(6), 721-728.

Tobón, G. J., Youinou, P., \& Saraux, A. (2010). The environment, geo-epidemiology, and autoimmune disease: Rheumatoid arthritis. Autoimmunity reviews, 9(5), A288-A292.

Copyright (C 2020, Journal of Scientific Research in Medical and Biological Sciences (JSRMBS), Under 
Too, C. L., Muhamad, N. A., Ilar, A., Padyukov, L., Alfredsson, L., Klareskog, L., . . . Group, M. S. (2016). Occupational exposure to textile dust increases the risk of rheumatoid arthritis: results from a Malaysian population-based case-control study. Annals of the rheumatic diseases, 75(6), 997-1002.

Turner, S., \& Cherry, N. (2000). Rheumatoid arthritis in workers exposed to silica in the pottery industry. Occupational and environmental medicine, 57(7), 443-447.

van der Linden, M. P., Le Cessie, S., Raza, K., van der Woude, D., Knevel, R., Huizinga, T. W., \& van der Helm-van Mil, A. H. (2010). Long-term impact of delay in assessment of patients with early arthritis. Arthritis \& Rheumatism, 62(12), 3537-3546.

Van Ede, A. E., Laan, R. F., Rood, M. J., Huizinga, T. W., Van De Laar, M. A., Denderen, C. J. V., . . Jacobs, M. J. (2001). Effect of folic or folinic acid supplementation on the toxicity and efficacy of methotrexate in rheumatoid arthritis: A forty-eight-week, multicenter, randomized, double-blind, placebo-controlled study. Arthritis \& Rheumatism: Official Journal of the American College of Rheumatology, 44(7), 15151524.

Viatte, S., Lee, J. C., Fu, B., Espéli, M., Lunt, M., De Wolf, J. N., . . Symmons, D. P. (2016). Association between genetic variation in FOXO3 and reductions in inflammation and disease activity in inflammatory polyarthritis. Arthritis \& Rheumatology, 68(11), 2629-2636.

Webber, M. P., Moir, W., Zeig-Owens, R., Glaser, M. S., Jaber, N., Hall, C., . . . Kelly, K. (2015). Nested case-control study of selected systemic autoimmune diseases in World Trade Center rescue/recovery workers. Arthritis \& rheumatology, 67(5), 1369-1376.

Wegner, N., Wait, R., Sroka, A., Eick, S., Nguyen, K. A., Lundberg, K., . . Venables, P. J. (2010). Peptidylarginine deiminase from Porphyromonas gingivalis citrullinates human fibrinogen and $\alpha$-enolase: Implications for autoimmunity in rheumatoid arthritis. Arthritis \& Rheumatism, 62(9), 2662-2672.

Weiss, G., \& Schett, G. (2013). Anaemia in inflammatory rheumatic diseases. Nature Reviews Rheumatology, 9(4), 205.

Yoo, S.-A., Kwok, S.-K., \& Kim, W.-U. (2008). Proinflammatory role of vascular endothelial growth factor in the pathogenesis of rheumatoid arthritis: prospects for therapeutic intervention. Mediators of inflammation, 2008.

Zen, M., Gatto, M., Domeneghetti, M., Palma, L., Borella, E., Iaccarino, L., . . . Doria, A. (2013). Clinical guidelines and definitions of autoinflammatory diseases: contrasts and comparisons with autoimmunity - a comprehensive review. Clinical reviews in allergy \& immunology, 45(2), 227-235.

Zhang, Y., Qiu, H., Zhang, H., Wang, L., Zhuang, C., \& Liu, R. (2013). Vascular endothelial growth factor A (VEGFA) polymorphisms in Chinese patients with rheumatoid arthritis. Scandinavian journal of rheumatology, 42(5), 344-348. 